This is an Accepted Manuscript of an article published by Taylor \& Francis in Translator on 8 May 2017 available online: http://www.tandfonline.com/. Article

DOI: http://dx.doi.org/10.1080/13556509.2017.1301846.

This document has been downloaded from TamPub.uta.fi The Institutional Repository of University of Tampere

Dancing with Technology. Translators' Narratives on the Dance of Human and Machinic Agency in Translation Work

Authors: Minna Ruokonen and Kaisa Koskinen

\title{
Authors' affiliation:
}

Foreign Languages and Translation Studies

Philosophical Faculty

University of Eastern Finland

Finland

\section{Corresponding author:}

Minna Ruokonen

Email: minna.ruokonen@uef.fi

Tel.: +358294 452152

Postal address: University of Eastern Finland, Agora 251, PO Box 111, FI-80101 Joensuu, Finland

\section{Notes on contributors}

Minna Ruokonen is a Senior Lecturer in English Language and Translation at the University of Eastern Finland. In her dissertation (Cultural and Textual Properties in the Translation and Interpretation of Allusions 2010, available online), she explored the translation of literary allusions in Finland of the 1940s and the 1980s, challenging the widely accepted idea that unfamiliar allusions mostly become confusing culture bumps. Her post-doctoral research focuses on the status of translators in society and the factors and strategies affecting it; since 2013, she has completed two extensive surveys in Finland, among translation students (277 respondents) and among professional translators (450 respondents) and published three articles on the subject. She is also one of the developers of the Finnish universities' Database for Teaching Methods in Translation and Interpreting (est. 2014) and is passionate about coming up with new ways of teaching translation and of supporting translation teachers in developing their teaching skills.

As of August 2016, Kaisa Koskinen is Professor of Translation Studies at the University of Tampere. She has authored several articles and monographs, e.g., Beyond Ambivalence. Postmodernity and the Ethics of Translation (2000, PhD), Translating Institutions. An Ethnographic Study of EU Translation (St.Jerome/Routledge 2008) and the text book UserCentered Translation (Routledge 2015; co-authored with Tytti Suojanen and Tiina Tuominen). Her current research interests include the concept of translatorial action in contemporary and historical perspectives, translatorial professions, as well as translation, user experience and affect.

\section{Disclosure statement}

The authors cannot think of any potential conflicts of interest. 


\title{
Dancing with Technology. Translators' Narratives on the Dance of Human and Machinic Agency in Translation Work
}

\begin{abstract}
This article examines translators' emotional narratives of their interaction with technology, focusing on how translators describe the machine's actions and agency as either diverging from or converging with their own, and whether this is experienced as positive or negative. The material comes from an exploratory project where the respondents were asked to write a short 'love letter/break-up letter' to a tool, application or aspect of work. Of the collected 106 letters dealing with technology, 61 assigned agency to technology; the relatively low number suggests that humans may be reluctant to consider the machine an agent. Expectedly, machinic agency is mostly viewed in a positive light in the letters reporting a convergence with that of the human user and, conversely, diverging agency is typically considered negative. However, letters deviating from this pattern suggest that the dance of agency between the human and the machine can be viewed in more complex terms. For example, a tool can do something unexpected but rewarding or change the human user in a positive way - or be too accommodating or passive when the user would wish for a more active partner. Further research from a non-anthropocentric perspective should provide relevant insights into translator-computer interaction.
\end{abstract}

Keywords: dance of agency, translator-computer interaction, translation technology, usability, affect

\section{Introduction}

Technological progress has had drastic effects on translation practice, making various tools and programmes an integral element of professional translators' work. Computer-assisted translation has been relatively well covered in research: we have some idea of how translation memory systems affect translators' work (Marshman 2014; Christensen and Schjoldager 2016) and how translators perceive the (dis)advantages of TM systems (Lagoudaki 2006; LeBlanc 2013). These days, however, translation memory software increasingly makes use of machine translation tools as well (see e.g. Bundgaard et al. 2016), potentially enhancing the machine's agentive status and reducing that of the human. This emergent practice is potentially challenging both for translators and translation scholars, as embracing the full potential of machine-driven translation seems to require a rethinking of human agency, and the understanding of translation as a predominantly human endeavour can be difficult to let go (Koskinen and Dam 2016). In more general terms, it has been argued that our world, increasingly technologically mediated, has entered a post-anthropocentric phase, which dramatically alters our identity as humans and calls for a reassessment of theoretical fundamentals in the humanities (Braidotti 2013). In Translation Studies, this shift, and the necessity of rethinking human agency, are particularly visible, as translation technology is rapidly displacing the centrality of the human translator. The issue of human vs. machinic agency is thus a crucial question for contemporary translation studies, and we urgently need to enhance our understanding of translator-computer interaction (O’Brien 2012).

The present authors' contribution to this quest focuses on translators' experiences and understandings of the interplay of agency between human and machine. We explore how translators experience, interpret and appraise their agency in an increasingly technologydriven work environment, and what kinds of agency they accord to their tools. To answer these questions, we have collected translators' narrative accounts of their emotional attachments to technological tools or other aspects of their working environment in the form 
of fictive love and break-up letters. Of the total 148 letters collected, 106 concern technology, and 61 of these 106 letters assign some agency to the machine. In this article, we analyse the dance of agency these 61 letters describe, with particular emphasis on how this dance and the two dance partners' roles and interaction are narrated and appraised.

'Dance of agency' is a concept developed by Andrew Pickering (1995) to analyse the interaction of human and non-human agents, previously applied to translation practice by Maeve Olohan (2011). Pickering focuses on the temporal process of resistance, accommodation and technological development. In contrast, the agents in our data seem more entangled and in a constant movement with one another. Our analysis thus focuses on a directional approach: whether the human and machinic agents are seen as convergent and moving in the same direction, or divergent and pulling in different directions. We further analyse whether these two types are appraised positively or negatively in the accounts, and whether the translators assign a dominant role to themselves or the machines.

The article unfolds as follows: section 2 explains the basic tenets of Pickering's approach, and we also discuss Olohan's application of it to Translation Studies, as well as the implications of a survey by Elizabeth Marshman (2014). In section 3 we describe our data and our method of analysis. In section 4 we report our findings, and in section 5 we discuss them and indicate some avenues for further research.

\section{Dance of Human vs. Material Agency}

Agency has been defined as the 'willingness and ability to act' (Koskinen and Kinnunen 2010, 6). Ability means that the actions of any agent are circumscribed and constrained by their social context as well as their embodied and cognitive limits (6-7). Ability could thus be stretched to cover machines and the functions they afford; the notion of will, however, presupposes an intentional, personal actor (6), excluding machines. This definition of agency is thus close to the concept of professional autonomy, or the ability to make 'work-related decisions on the basis of [one's] professional knowledge and values' (Weiss-Gal and Welbourne 2008, 284) - in other words, to control and manage one's work, its processes and outputs.

The above definition can be criticised as foregrounding the human agent and ignoring the increasing autonomy of smart machines (Braidotti 2013, 43). This human-focused understanding is also the target of Andrew Pickering's critique. He perceives agency as something that can be either human or material (Pickering 1993, 1995). While human agency still involves intentions and goals, material or machinic agency requires no intentionality but is simply manifested in actions (Pickering 1993, 565-566, 577), such as in the features or functions of TM or MT software. ${ }^{1}$

Pickering's view of agency is useful for describing the interaction between human and nonhuman agency, which emerges as a dialectic of resistance and accommodation (Pickering $1993,569 ; 1995,21-22)$. Resistance occurs when, for example, software fails to function in the way expected by users. Users may then have to accommodate their own behaviour: try out

\footnotetext{
${ }^{1}$ As Pickering $(1993,562-563 ; 1995,11$; see also Olohan 2011, 353) observes, a similar approach is adopted in the actor-network theory (ANT), where the actors constituting the network can be anything from humans, organizations and institutions to tools and even texts - in short, anything that can act or can be put into action to affect other actors. For applications of ANT to translation research see, for example, Buzelin (2005) and Abdallah (2011).
} 
other functions, work around the feature, consult software documentation, or give up trying to achieve the aim. If the software failure is severe, a patch or an update may need to be developed, leading to an accommodation in the software. This pattern of resistance and accommodation is called the dance of agency (or the 'mangle of practice'; Pickering 1993, 569), which is the driving force behind scientific and technological innovations (see case studies in Pickering 1995).

Maeve Olohan (2011) applies Pickering's ideas to the interplay of translators and translation technology, analysing a discussion thread concerning the launch of SDL Trados Studio 2009. The posts in Olohan's data illustrate how a smoothly running process, such as installation of new software, offers the human agent the feeling of being in control (348). In contrast, when problems occur, the posts start describing the software as a distinct agent that resists human agency (see examples in section 3 below) and forces translators to modify their behaviour.

Pickering's dance of agency is markedly temporal and progressional by nature: resistance and accommodation are stages leading to improved machinery $(1995,14)$. Olohan's study also describes a temporal process: the launch of a new product, its resistance, and accommodation by the users. In regular translation practice, in contrast, the human and the translation tools coexist in a long-term relationship and function more or less in concert. While observations of actual translation practice could reveal micro-movements of resistance and accommodation, in narrative accounts such as our data, the dialectic unfolds in a slightly different manner: in descriptions of a more or less harmonious and more or less positively appraised dance together. Thus, while some indications of temporality emerged in our data and are taken into account, the present article focuses on resistance and accommodation in terms of convergent and divergent directions and rhythms, rather than as a process. Our respondents' attitudes towards technological change and technology acceptance are covered elsewhere (Koskinen and Ruokonen 2017).

Olohan's (2011, 348-349) study further illustrates how individuals may experience varying degrees of being 'in control' or being 'offered resistance' when using a program. The experiential level is crucial in understanding the contemporary translators' workplace. Recent neuroscience has accumulated evidence of the central role of emotions in how we make sense of our environment and decide how to act (Wetherell 2012,45). Thus, it is not only important to analyse the degree of translators' agency but also to understand how they experience and appraise their agency. Olohan $(2011,353-354)$ calls for observational studies conducted in the workplace. We agree, but we also maintain that a narrative approach has its values. A screen recording may indeed capture the degree of resistance a tool is offering and the translator's acts of accommodation; however, narrative methods are more likely to reveal how the translators experience this dance of agency, and what kinds of attitudes and emotions it evokes in them.

The issue of human versus machinic agency is also implicitly evoked in Elizabeth Marshman's (2014) survey of language professionals and technologies. The respondents' overall attitudes towards technology were not indicative of technology offering much resistance: most respondents felt technologies in general to be either 'assets' (39\%) or 'overall assets' (38\%; p. 389). However, the respondents also believed that technology had influenced different aspects of their work, including their sense of control over their work, which, as pointed out above, is closely related to professional autonomy and agency. Of those respondents who had noticed technology affecting their work, $61 \%$ to $77 \%$ felt more in control of the amount and quality of their work, as well as their tasks and working methods 
(390-391). However, a considerable proportion (23\% to 39\%) conversely felt less in control over these four aspects. As in Olohan's data $(2011,352)$, there was considerable variation (Marshman 2014, 391); it would thus seem that for some individuals, the technologies they used improved their sense of control while for others, technologies curtailed their sense of control, and quite possibly of agency. We believe that analysing translators' narratives can offer further insight into how different translators experience technology and its impact on their work and agency.

\title{
3 Data and Method
}

The present study is based on data collected by requesting professional translators and translation students to write a love letter or a break-up letter to the greatest, most lovable or, conversely, the most annoying tool or element of their translation work, as illustrated by the following excerpt from the English instructions:

\begin{abstract}
Picture yourself in the space where you normally work with your translation assignments. Try to capture your first, intuitive reaction to the following question: What is the greatest tool or support for you when you are translating? What gives you the most pleasure? What would you be most reluctant to lose?

Or do some reverse thinking: What is the most annoying hindrance you need to deal with? Which tool, artefact or element is emotionally the most unpleasant? What would you be happy to get rid of?
\end{abstract}

This qualitative, free-form method comes from usability research, where it was designed to bring out the emotions users attach to devices and objects (see Hanington and Martin 2012, 114). Our data were first gathered to test the applicability of the method and to explore translators' affective commitments in general. Subsequently, the data were reanalysed from the perspective of translators' technology acceptance (Koskinen and Ruokonen 2017, 11).

Data collection took place during Spring 2014 in four different settings, producing a total of 148 letters from 102 respondents. Participation was entirely voluntary in each group, and the respondents were free to write either a love letter or a break-up letter or both. The respondents included

- 44 translators in the European Union institutions (code: EU);

- 26 business translators working on the Finnish market (code: FI);

- 21 MA-level translation students in Finland (code: MAFI); and

- 11 MA-level translation students in Ireland (code: MA). ${ }^{2}$

Apart from the Finnish translator data, which was collected through an on-line survey administered via social media, the data collection took place in face-to-face contacts, in connection with a training session on the future of translation technology (EU translators), a visiting lecture on localisation and usability (Irish MA students) and a visiting lecture on fieldwork methods (Finnish MA students). Apart from the Finnish MA students, the settings may thus have primed the respondents to foreground technology (see Koskinen and Ruokonen

\footnotetext{
2 The respondents will be referred to by sub-group and code number only, for example FI-61 for Finnish business translators. Further identifying information has been omitted so as not to expose the respondent's identity. All quotes from participants marked with FI have been translated by the authors.
} 
2017 for details). However, for the present study, this priming is actually an advantage. As the respondents were instructed to address an emotive letter to a tool or element of their choice, the method further encouraged them to personalise a tool and to consider how they experience working with it. The data should thus foreground machinic agency, as well as respondents' experiences of it.

As narratives of emotions, the love and hate letters represent reported affect and discursively constructed tales of emotion; they do not allow direct access to the respondents' psychological states. The letters also constitute retrospective material as opposed to data collected in the context of actual technology use. On the other hand, such retrospective and holistic research material can be revealing in terms of long-term interactions that have made strong impressions on the respondents. This makes the letters relevant for analysing how translators experience the material agency of tools that are central to their work. It needs to be noted, however, that in using narrative accounts as data, and focusing on experiences, we foreground the human, and diverge from Pickering's project.

An Excel spreadsheet was created to organize the entire set of 148 letters for analysis. The letters were first divided into two main categories: love vs. break-up letters; a third, ambivalent category became necessary as some letters were so ambivalent in tone that enforcing the binary division would have been misleading. Next, the letters containing technology references were filtered from the data. 'Technology' was defined broadly to reflect the variety in the data. In addition to prototypical translation technology such as translation memory software and machine translation systems, we also included other software (word processing, time management systems and operating systems), search tools and databases (the internet, Google, IATE), hardware (laptop, keyboard) and references to 'computers' or 'IT' in general. A total of 106 letters contained a reference to technology, either as the central topic or as an aside (see Table 1 below). This probably reflects technology's major role in translators' work.

\begin{tabular}{|l|l|l|l|l|}
\hline & $\begin{array}{l}\text { Love } \\
\text { letter }\end{array}$ & $\begin{array}{l}\text { Ambivalent } \\
\text { letter }\end{array}$ & $\begin{array}{l}\text { Break-up } \\
\text { letter }\end{array}$ & Total \\
\hline $\begin{array}{l}\text { EU } \\
\text { translators }\end{array}$ & 27 & 1 & 13 & $\mathbf{4 1}$ \\
\hline FI translators & 16 & 3 & 12 & $\mathbf{3 1}$ \\
\hline MA students & 16 & 3 & 15 & $\mathbf{3 4}$ \\
\hline Total & $\mathbf{5 9}$ & $\mathbf{7}$ & $\mathbf{4 0}$ & $\mathbf{1 0 6}$ \\
\hline
\end{tabular}

Table 1: Technology letters (n) by category and respondent

We then worked our way through these 106 letters, looking for cases where a tool had been assigned some agency, and these 61 letters form the bulk of the data analysed in this article (in section 4.4, we also consider some additional examples). At all stages of the analysis, we applied a consensus method of discussing and debating each item until agreement on its classification was reached. Taking our cue from Olohan's (2011) examples, we used the following markers as indications of agency (italics by the authors):

1) The tool is a subject in an active clause with a verb expressing action (cfr. Olohan 2011, 348: 'the Editor does not handle docs; it imports them alright but then wants to store everything in its own [...] format'). The tool can be the dominant agent: 'You have the answers to all my questions[,] well, almost all, that is. If you can't solve it 
nobody can!' (EU-22); or the tool can adopt an assisting role: 'For once, a translation tool -- adjusts itself at least reasonably well to the different needs of very different projects. -- [This tool] helps me to act consistently and clearly' (FI-60).

2) The tool has the power to change the respondent: 'I hate the way that using this tool makes me lazy and less creative --' (EU-43); 'Your presence soothes me, and finding answers quickly makes me very happy' (MAFI-90).

3) The tool is described as a reciprocating partner in an interaction (cfr. Olohan 2011, 348: 'it does not ask you to open a MultiTerm file'), as in 'When no term bank helps, when I'm completely deadlocked -- that is when you come along, my dear Google image search! In most cases I get an answer from you in the blink of an eye and in most cases it's even the correct one' (MAFI-84).

4) Cases where a tool does not act as expected by the user (cfr. Olohan 2011, 348-349), which are prime examples of Pickering's resistance: 'Sometimes you have been wilful -- you have not allowed me to change your settings to suit my preferences' (FI-54).

Of these markers, 1) was by far the most common indicator of agency, probably because the letter format encouraged the respondents to personalise the tools.

Tools depicted as helpers created difficulties in categorisation. We chose a conservative approach: cases where the tool was personalised as the subject of an active clause were not regarded as agentic if the wording made it evident that the tool was simply a passive aid or repository of knowledge, as in 'translation memory that just regurgitates the stupidities others decided to save' (EU-2); here, the ultimate agents appear to be the other humans who saved 'the stupidities'. Similarly, some letters emphasised the limits of a tool's agency, describing a tool as a 'humble servant' (FI-63) or '[without] a consciousness of your own' (EU-39).

Instances of tools being attributed human qualities were not regarded as agency markers unless the instance also fulfilled one of the criteria 1) to 4) above. Similarly, expressions of an emotional tie to the tool in question were not counted as indications of agency if the tool simply remained the object of affection, such as in 'I cannot say I am really in love with you yet, but I am steadily going into that direction' (EU-37). In contrast, if emotion was described as a change in the respondent caused by the tool (see MAFI-90 in category 2 above), the object of affection was seen as agentic.

We acknowledge that the decision to leave these instances aside is debatable. However, we felt that as the letter format encouraged personification, assuming assignment of agency in cases such as the above would have risked over-interpreting. Excluding such fuzzy cases also allows us to see more clearly the dance of agency in those letters where both parties are clearly seen as agentic.

The 61 cases of machinic agency were then further classified based on 1) the directions of the human and machine agency (convergent with or diverging from each other) and 2) whether this convergence/divergence was characterized as positive or negative by the respondent. The resulting 2-by-2 matrix contains the quadrants convergent-positive, convergent-negative, divergent-positive and divergent-negative, as illustrated in Table 2 below, with short examples in each quadrant. 


\begin{tabular}{|c|c|c|}
\hline & Convergent & Divergent \\
\hline Positive & $\begin{array}{l}\text { 'I love you -- You help me } \\
\text { make up my mind when I } \\
\text { am hesitating and speed up } \\
\text { my work.' (EU-16, love } \\
\text { letter) }\end{array}$ & $\begin{array}{l}\text { 'My memory grows feebler } \\
\text { day by day, but you do not } \\
\text { forget. Please never leave } \\
\text { me alone again.' (FI-55, } \\
\text { love letter) } \\
\text { '[S]ometimes you surprise } \\
\text { me positively by finding } \\
\text { expressions or words I've } \\
\text { not found elsewhere --' } \\
\text { (MAFI-96, love letter) }\end{array}$ \\
\hline Negative & $\begin{array}{l}\text { 'I'd rather you didn't let } \\
\text { me visit trivial photo } \\
\text { sharing websites and such } \\
\text { when I'm in the middle of } \\
\text { an assignment --' (MAFI- } \\
\text { 101, ambivalent letter) }\end{array}$ & $\begin{array}{l}\text { '[U]sing this tool makes } \\
\text { me lazy and less creative - } \\
\text {-' (EU-43, break-up letter) } \\
\text { 'It feels like [computers } \\
\text { and software] never } \\
\text { function - at least in the } \\
\text { way they should.' (FI-45, } \\
\text { break-up letter) }\end{array}$ \\
\hline
\end{tabular}

Table 2: Illustration of the analysis matrix

\section{Results}

\subsection{Overview}

Of the 106 technology-related letters, 61 accorded some agency to a tool. The fact that a tool was only accorded agency in slightly over half of the letters may partly be due our conservative assessments, but the figure still seems low, given that the letter format could have been expected to encourage the respondents to personify tools and give them rhetorical agency. We return to this issue in section 5.

Table 3 below illustrates the frequencies in each quadrant of the matrix. Classification was mostly straightforward, but there were some instances where the agency of a tool was described as partly convergent and partly divergent (see MAFI-101 in section 4.4 below). Changes in the respondent caused by a tool were classified as divergent. 


\begin{tabular}{|l|l|l|l|l|}
\hline \multirow{4}{*}{ Positive } & \multicolumn{2}{|l|}{ Convergent } & \multicolumn{2}{l|}{ Divergent } \\
\cline { 2 - 5 } & Love letters & 18 & Love letters & 8 \\
\cline { 2 - 5 } & Ambivalent letters & 0 & Ambivalent letters & 0 \\
\cline { 2 - 5 } & Break-up letters & 2 & Break-up letters & 0 \\
\cline { 2 - 5 } Negative & Sub-total & $\mathbf{2 0}$ & Sub-total & $\mathbf{8}$ \\
\hline & Love letters & 0 & Love letters & 3 \\
\cline { 2 - 5 } & Ambivalent letters & 1 & Ambivalent letters & 3 \\
\cline { 2 - 5 } & Break-up letters & 0 & Break-up letters & 26 \\
\cline { 2 - 5 } & Sub-total & $\mathbf{1}$ & $\mathbf{3 2}$ \\
\hline
\end{tabular}

Table 3: Cases of material agency in the data by type

Unsurprisingly, nearly all of the positive comments $(n=28)$ occurred in the love letters and most of the negative comments in the break-up letters. It also makes sense that the respondents mostly experienced the technology's agency as positive as long as it converged with their own agency $(n=20)$. Conversely, if the technology's agency diverged from the intentions of the respondents, they described this negatively $(n=32)$.

However, the matrix also includes indications of a more complex relationship between the human and the machine. In eight cases, technology having a will of its own elicited positive comments and in one case technology's converging agency was experienced as negative (MAFI-101 in Table 2 above). Moreover, in three letters not included in the matrix, technology was described as having no agency at all and this was experienced as negative.

We next look more closely at each group of letters. We begin with the two groups that conform to expectations: convergent and positive, divergent and negative. We then direct our attention to the indications of complexity. In each group, we will pay particular attention to the division of agency, considering who is seen to be in charge, man or machine, and how this is experienced by the respondents.

\subsection{Dancing together: Convergent Agency seen as positive}

In 20 letters, the tool's agency was seen to converge with that of the respondent and this convergence was described in a positive light, as illustrated by the following examples:

Dear computer \& two huge screens,

Although it takes you 20 minutes to start up every morning and my two big screens stare empty at me, I look forward to working on you. When you eventually come to life, you offer me an abundance of tools that help me in translation, make it quicker and less painful and all that served on my two beloved screens of 21 inches. (EU-27)

Dear dictionary (electronic/print),

Our journey together has been long and will hopefully continue for many years to come. You've helped me in challenging situations and supported me in many translation assignments. It makes me particularly happy when I find an equivalent for a really difficult term in you. (MAFI-97)

Thus, in a third of all the letters where tools were accorded some agency, the tool's agency emerged as convergent with that of the respondents': the tools speeded up their work and 
made it more efficient, provided search results, and in general made working conditions more pleasing.

A closer analysis of the 20 convergent and positive letters indicated that in most of these cases $(\mathrm{n}=12)$, the respondents felt that the tool was a support and an aid, but it was ultimately the human translator who made the decisions (see Table 4 below).

\begin{tabular}{|l|l|}
\hline & $\mathbf{n}$ \\
\hline Human & 12 \\
\hline Both & 6 \\
\hline Machine & 2 \\
\hline & $\mathbf{2 0}$ \\
\hline
\end{tabular}

Table 4: Dominant agent in convergent and positive letters

In six letters, the human and the tool were placed on equal footing, as indicated by phrases such as 'I feel like, every time I am doing a translation, you and I are a team' (MA-74), or 'while you're often useful in other contexts, during the translation process we must keep our distance from each other' (MAFI-99).

There were only two letters in this group where the machine's dominant agency was experienced as positive. Even in these letters, quoted below, the respondents do not see the translation process as machine-driven but qualify the role of technology by indicating the centrality of the human translator: it is their translation work that is speeded up and their time that is saved.

You have the answers to all my questions well, almost all, that is. If you can't solve it nobody can! To think of all the time you save me, no need to browse through paper dictionaries, no need to call people, ask for help. (EU-22)

[Y]ou often provide me very valuable help with my day-to-day translation work. You tell me whether a term or a phrase has already been translated by an institution (or rather, by a translator working in a European institution) which speeds up my task considerably. (EU26)

In sum, convergent agency is considered positive as long as the human leads - or, conversely, as long as the human partner is happy with the direction, she perceives herself as the one who leads the dance.

\subsection{Out of Sync: Divergent Agency seen as negative}

Whereas convergent agency was almost always described in positive terms, a tool having a mind of its own received mostly negative comments, in 32 letters overall, making this the quadrant with the most letters in the matrix. The comments were mainly related to the way a tool did not function as quickly and efficiently as the respondent wished or did not have the functions the user would have needed:

Damn you, you slow internet connection,

You slow down my translation work considerably --. You may get stuck any time, usually just when a deadline is approaching, which is why I'm thinking I'll replace you with a faster version. (MAFI-95) 
Monolingual version of Microsoft Word,

I just want to let you know that, every time I am trying to write a text which is [not English], you make my life very difficult. I understand you are designed to highlight typos, but as I do not have the [--] language version of you, you actually delay and hinder my productivity. (MA-74) ${ }^{3}$

Dear style tags, I hate you!

-- I cannot let you go, you are constantly popping up there, on my screen, and I have to reproduce you in my target text all the time. Losing precious time to focus on what really matters, on the meaning of the text I'm translating. (EU-14)

There were also two examples where the machine had changed the respondents or their emotional state in a negative way: one respondent already quoted above complained that 'using this tool makes me lazy and less creative --' (EU-43), and another felt that 'you always manage to make me feel insecure and inadequate although the fault is clearly yours' (FI-48).

Most of the letters in this group also conveyed a sense of the tool being more dominant than the human translator, as shown in Table 5 below. To use Pickering's terminology, the tool offers resistance, and the translator is forced to accommodate the tool. In Pickering's studies, accommodations were seen in a neutral light; in these letters, they are experienced as negative by the respondents, and the dance partners are depicted as being out of sync.

\begin{tabular}{|l|l|}
\hline & $\mathbf{n}$ \\
\hline Human & 2 \\
\hline Ambivalent & 6 \\
\hline Machine & 24 \\
\hline & $\mathbf{3 2}$ \\
\hline
\end{tabular}

Table 5: Dominant agent in divergent and negative letters

\subsection{Indications of Complexity}

The above two groups conformed to expectations: the respondents expressed positive feelings when machines helped them accomplish what they wanted, and negative feelings when machines resisted them. However, as pointed out in section 4.1 above, there were also three types of letters offering glimpses of a more complex relationship. While these three types only amount to a total of 12 letters, this is a tenth of all 106 of the technology-related letters, a major minority.

Firstly, in eight love letters, the divergent agency of the two partners was depicted in a positive light, acknowledging that a tool can do something unexpected but rewarding, or act more reliably than the respondent:

[Y]ou surprise me positively by finding expressions or words I haven't found elsewhere (MAFI-96)

My memory grows feebler day by day, but you do not forget. (FI-55)

\footnotetext{
${ }^{3}$ Language omitted to protect the respondent's anonymity.
} 
Particularly the internet's divergent agency gave rise to varying reactions. Some respondents expressed annoyance at the way the internet lured them astray, but one respondent, in contrast, acknowledged the internet's distractions as welcome breaks:

Particularly on the internet it's easy to get 'lost along the way' and start exploring all kinds of sites that are only remotely relevant. -- On the other hand, thanks to the meandering nature of the internet, it's easy to take microbreaks to visit some of the more entertaining sites. So the day just flies by and it feels like you haven't had to work at all. (MAFI-61)

Two letters commenting on the changes that a tool had caused in them were also addressed to the internet and viewed the changes in a positive light. One of these letters (MAFI-90) was already quoted in section 3 above ('your presence soothes me'); the other one reads as follows:

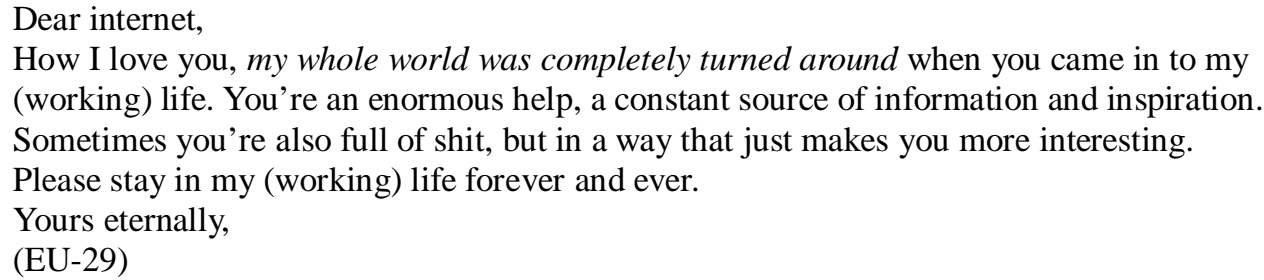

The second type of letters with indications of complexity includes the one convergent letter that describes the lack of machinic agency in a partially somewhat negative light (partly quoted in Table 2 above). This ambivalent letter also concerned the allure of the internet. The respondent first praises the convergent agency of the internet, but then goes on to deplore the machine's inability to diverge from her will even when it would be in her best interest:

Dear internet, damn internet,

Dear internet,

With your masses of information you are both dear and damned. Without you, I couldn't do any translation work, but it's also because of you that assignments take more time than they should. You've saved me multiple times, offered me alternative solutions and been my support through the most fricking assignments. However, I'd rather you didn't let me visit trivial photo-sharing websites and such when I' $m$ in the middle of an assignment. (MAFI-101)

Thirdly, among the letters assigning no agency to a tool (and thus not included in the matrix in Table 3 above), there were three cases where a tool's lack of agency was experienced as negative. All of these letters characterised translation memories or databases as passive and unhelpful sources of information that 'just regurgitat[e] the stupidities others decided to save' (EU-2, see section 3 above) or offer ' $3-4-5$ different options' for a term without helping to select the correct one (EU-4).

All in all, while the respondents appear happy with tools whose agency supports their own, some of them acknowledge that interaction can be rewarding even when the tool's agency is divergent from the user's or changes the user - and that technology's lack of agency can be negative.

\section{Discussion and Conclusions}

This exploratory project complements previous research with several interesting implications. A total of 106 letters, or over $70 \%$ of the original 148, contained a reference to technology, which probably reflects technology's major role in translators' work. However, only 61, or slightly over half, of the technology-related letters assigned some agency to machines. This suggests a reluctance to grant agency to machine, a tendency also observed by Koskinen and 
Dam (2016) in translation scholars (cfr. Braidotti 2013, 104).

In the descriptions of the machine's agency, the two largest groups were convergent/positive and divergent/negative. This is in line with Olohan's (2011) findings, where translators also appreciated smoothly functioning software and made negative comments when the program refused to act as expected. Both our and Olohan's results also highlight the role of emotions in the day-to-day dialectic of resistance and accommodation in the dance of human and technology, while Pickering $(1993,1995)$ saw the dance of agency as a long-term process and described it in neutral terms.

Letters depicting the human struggling in vain with a resistant machine can be linked to a recurrent cultural image of the man/machine relationship. It is thus hardly surprising that this group was dominant in our data. Narratives of resistance are also likely to be told because negative affects create memorable moments and represent shared cultural repertoires of sensemaking (Wetherell 2012, 94). In Pickering's thinking, resistance and accommodation are perceived as necessary steps leading to improvements and innovations, and it is noteworthy that this element also emerges in a number of translators' narratives that show a willingness or expectation for things to change for the better, either through the respondent's own actions (e.g. MAFI-95 in section 4.3 above) or through software development. This optimistic view of progress was also seen in our previous analysis of the technology letters, where we looked at the respondents' attitudes towards technological change and discovered a tendency to consider the past conditions inferior to the present, suggesting that technological progress was appreciated rather than deplored (Koskinen and Ruokonen 2017, 17).

The machine can also change the human for the better - or for the worse; our data contained examples of both, but it is perhaps particularly interesting that the respondents had experienced some changes as positive. Overall, the results emphasise the variety of individual experience. This is in line with Olohan's (2011) data, where translators expressed differing opinions on the usability of the same software, and with Marshman's (2014, 390-391) survey, where over half of the respondents felt that they were more in control of their work thanks to technology, but quite a few held opposite views.

Perhaps the most interesting implications of our data come from the letters where the dance of agency emerged as more complex than in previous research. They draw attention to unanticipated reactions: a tool's divergent agency can be a welcome support or make the human user's work more varied and enjoyable or change the human for the better, and, conversely, too passive or compliant a tool can create trouble and annoyance. Further research is needed to discover how common such experiences are and in what kinds of situations they occur. These indications of complexity in our dualistically constructed analysis also signal a necessity to move away from simplified man-versus-machine conceptions in order to capture the intricate interplay of human and machinic forces in contemporary translation workplaces.

\section{References}

Abdallah, Kristiina. 2011. "Quality Problems in AVT Production Networks: Reconstructing an Actor-Network in the Subtitling Industry." In Audiovisual Translation in Close-up: Practical and Theoretical Approaches, edited by Adriana Serban, Anna Matamala, and Jean-Marc Lavaur, 173-188. Bern: Peter Lang.

Buzelin, Hélène 2005. "Unexpected Allies: How Latour's Network Theory could Complement Bourdieusian Analysis in Translation Studies." In Bourdieu and the Sociology of Translation and Interpreting, edited by Moira Inghilleri. Special issue of The Translator 
11(2): 193-218.

Braidotti, Rosi. 2013. The Posthuman. Cambridge: Polity Press.

Bundgaard, Kristine, Tina Paulsen Christensen, and Anne Schjoldager. 2016. "Translator-

Computer Interaction in Action - an Observational Process Study of Computer-Aided

Translation." Journal of Specialised Translation 25: 106-130.

http://www.jostrans.org/issue25/issue25_toc.php. Accessed 31 January 2017.

Christensen, Tina Paulsen, and Anne Schjoldager. 2016. "Computer-Aided Translation Tools the Uptake and Use by Danish Translation Service Providers." Journal of Specialised Translation 25: 89-105. http://www.jostrans.org/issue25/issue25_toc.php. Accessed 31 January 2017.

Hanington, Bruce, and Bella Martin. 2012. Universal Methods of Design: 100 Ways to Research Complex Problems, Develop Innovative Ideas, and Design Effective Solutions. Beverly, MA: Rockport.

Koskinen, Kaisa, and Helle V. Dam. 2016. "Academic Boundary Work and the Translation Profession: Insiders, Outsiders and (Assumed) Boundaries." Journal of Specialised Translation 25: 234-267. http://www.jostrans.org/issue25/issue25_toc.php.

Koskinen, Kaisa, and Tuija Kinnunen. 2010. "Introduction.” In Translators' Agency, edited by Tuija Kinnunen and Kaisa Koskinen, 4-10. Tampere: Tampere University Press. http://urn.fi/urn:isbn:978-951-44-8082-9. Accessed 31 January 2017.

Koskinen, Kaisa, and Minna Ruokonen. 2017. 'Love Letters or Hate Mail? Translators' Technology Acceptance in the Light of their Emotional Narratives." In Human Issues in Translation Technology, edited by Dorothy Kelly, 8-24. Abingdon: Routledge.

Lagoudaki, Elina. 2006. “Translation Memories Survey 2006: Users' Perceptions around TM Use." Paper presented at ASLIB International Conference Translating and the Computer 28, London, November 2006. http://mt-archive.info/05/Aslib-2006-Lagoudaki.pdf. Accessed 31 January 2017.

LeBlanc, Matthieu. 2013. "Translators on Translation Memory (TM). Results of an Ethnographic Study in three Translation Services and Agencies." Translation \& Interpreting 5(2): 1-13. http://www.trans-int.org/index.php/transint/article/view/228. Accessed 31 January 2017.

Marshman, Elizabeth. 2014. "Taking Control: Language Professionals and their Perception of Control when Using Language Technologies." Meta: journal des traducteurs / Meta:

Translators' Journal 59(2): 380-405. doi: 10.7202/1027481ar.

O’Brien, Sharon. 2012. “Translation as Human-Computer Interaction.” Translation Spaces, 1(1): 101-122. doi: 10.1075/ts.1.05obr.

Olohan, Maeve. 2011. "Translators and Translation Technology: The Dance of Agency." Translation Studies 4(3): 342-357. doi: 10.1080/14781700.2011.589656.

Pickering, Andrew. 1993. "The Mangle of Practice: Agency and Emergence in the Sociology of Science." American Journal of Sociology 99(3): 559-589.

Pickering, Andrew. 1995. Mangle of Practice: Time, Agency and Science. Chicago: University of Chicago Press.

Weiss-Gal, Idit, and Penelope Welbourne. 2008. "The Professionalisation of Social Work: a Cross-National Exploration." International Journal of Social Welfare 17(4): 281-290. doi: 10.1111/j.1468-2397.2008.00574.x. 
Wetherell, Margaret. 2012. Affect and Emotion: A New Social Science Understanding. London/Thousand Oaks/New Delhi: Sage. 